\title{
Combined thermoelastic and thermographic data for the evaluation of crack growth in industrial components
}

\author{
U. Galietti, D. Modugno \\ Mechanical and Management Engineering, Politecnico di Bari \\ Viale Japigia 182, Bari-Italy
}

ABSTRACT:

galietti@poliba.it, dmodu@poliba.it

The application of infrared thermography as a non-destructive method to detect the occurrence of damage and to investigate the fatigue process of materials has become popular and has been widely investigated in literature. Thermography has clearly shown to be a powerful tool for the characterization of structural material properties such as fatigue limit. Many previous works from literature have gone into the relation between the damage in the material and the temperature arising as result of internal energy dissipation.

On the other hand, thermoelastic stress analysis has become in the last years a well established technique for the determination of the stress field in mechanical components, even with an high geometrical complexity.

The present work starts from the observation that damage in the material results both in a change in superficial temperature and in a change of the stress field. A differential infrared camera, DeltaTherm 1560 by Stressphotonics, has been used to acquire both thermographic and thermoelastic data from industrial mechanical components subjected to a fatigue cyclic load.

Infrared signal from the samples has been acquired with a time gap of few minutes, in order to have a continuous monitoring of the crack growth in the sample under investigation until the occurrence of the failure. A comparison of thermographic and thermoelastic data shows that the change in temperature field is strictly related with the change in the pattern of the stresses distribution due to the evolution of the damage in the material.

Experimental data are provided from welded joints and samples in composite material.
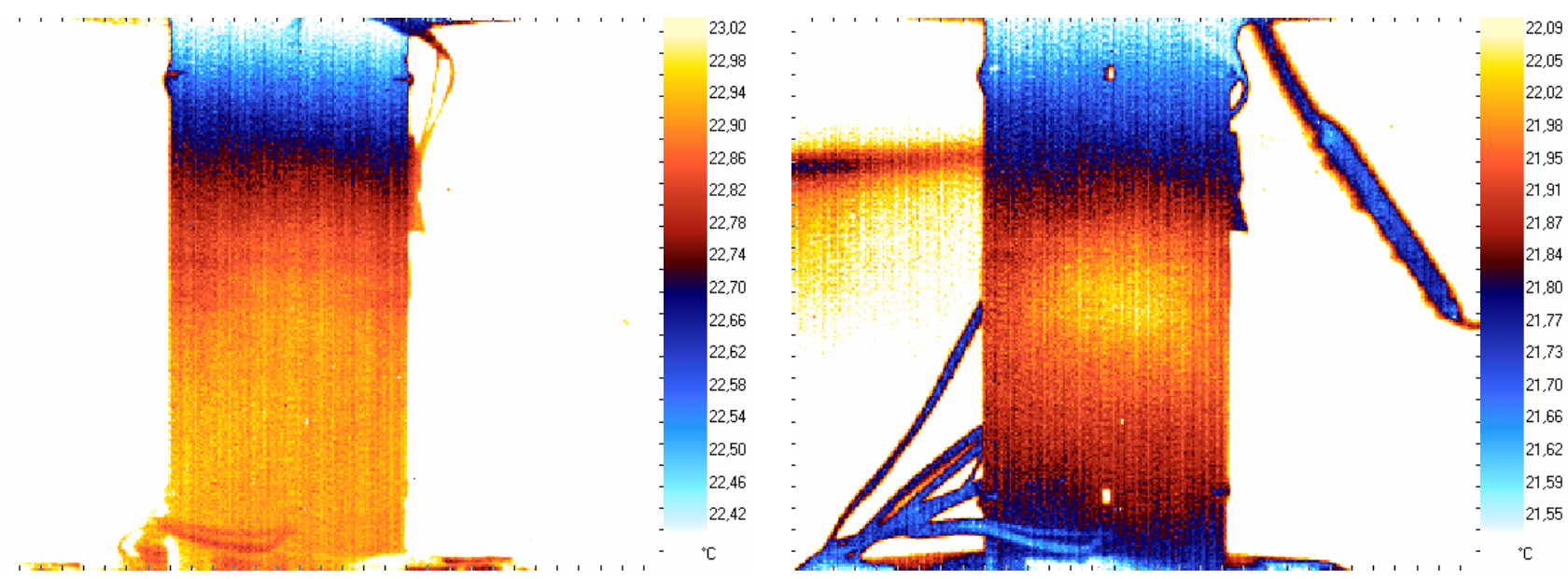

Figure 1- Thermographic image of a welded joint, (on the left) at the beginning of the test, (on the right) just before the occurrence of the failure. 


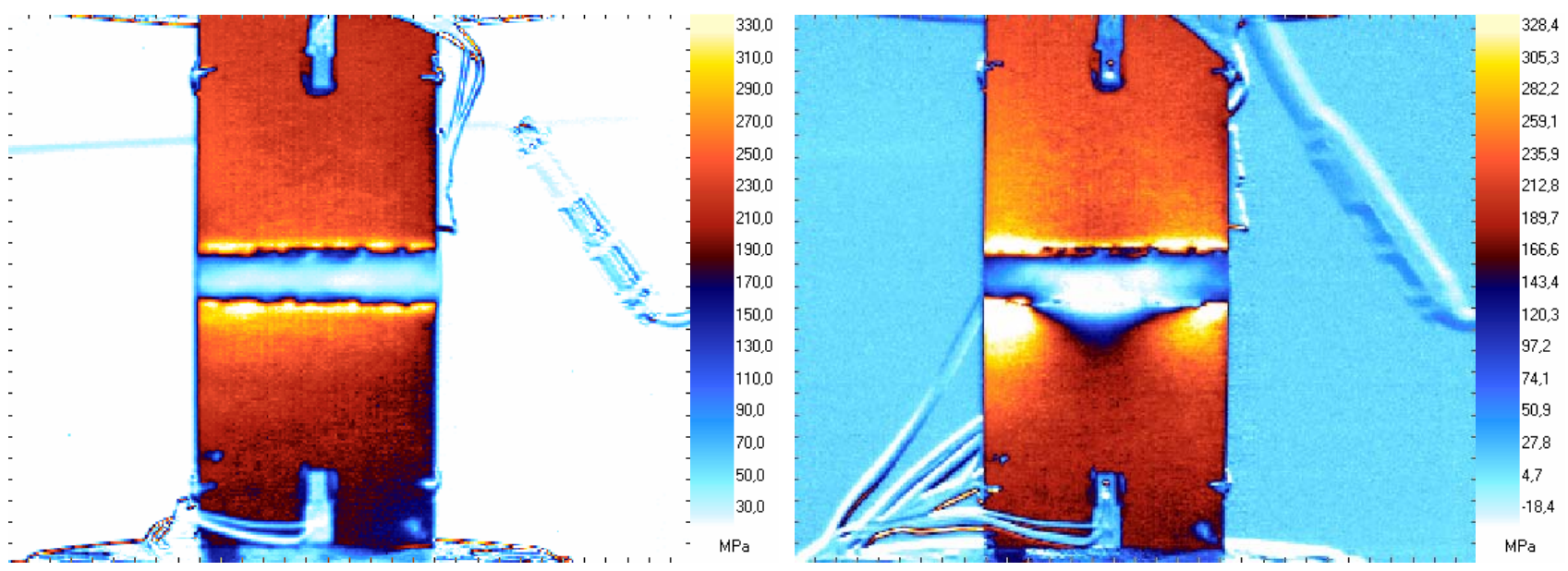

Figure 2- Thermoelastic image of a welded joint, (on the left) at the beginning of the test, (on the right) just before the occurrence of the failure.

\section{REFERENCES}

[1] M. P. Luong, "Fatigue limit evaluation of metals using an infrared thermographic technique", Mechanics of Materials, 28, 1998, p. 155-163 (Journal).

[2] G. La Rosa, A. Risitano, "Thermographic methodology for rapid determination of the fatigue limit of materials and mechanical components", International Journal of Fatigue, 22, 1, 2000, p. 65-73 (Journal).

[3] J.C. Krapez, D. Pacou and G. Gardette, "Lock-in thermography and fatigue limit of metals". Quantitative infrared thermography 5: QIRT'2000.

[4] A. Chrysochoos, H. Louche, "An infrared image processing to analyse the calorific effects accompanyng strain localisation", International Journal of Engineering

Science, pp. 1759-1788, 38, (2000).

[5] A.E. Morabito, "Analisi termomeccanica degli effeti termoelastici e dissipative associati al comportamento a fatica della lega di alluminio 2024 T3", PHD thesis, Universita'degli Studi di Lecce, 2003, in italian.

[6] Stanley, P., Chan, W.K., "Quantitative stress analysis by means of the termoelastic effect", Journal of Strain Analysis, Vol. 20 (3), 1985, pp. 129-137

[7]. Maldague, X.P.V., "Theory and practice of infrared technology for nondestructive testing", 2001 John Wiley \& Sons Inc., ISBN 0-471-18/190-0.

[8]. Harwood, N., Cummings, W.M., "Thermoelastic Stress Analysis", Adam Hilger IOP Publishing.

[9] DeltaTherm user manual. 